\title{
Packet Microwave Layer 1 and Layer 2 Throughput in E-band for Mobile Broadband Communications
}

\author{
Sawadogo Moumouni ${ }^{1,2 *}$, Sanou $\mathrm{SR}^{1,3}$, Kebre BM${ }^{1}$, Doumounia $\mathrm{A}^{1}$, Illa $\mathrm{K}^{4}$ and Zougmoré $\mathrm{F}^{1}$ \\ ${ }^{1}$ Department of Communications, Laboratoire de Matériaux et Environnement (LAME), Université Ouaga I, Pr Joseph Ki-Zerbo, Ouagadougou Burkina-Faso. \\ ${ }^{2}$ Telecel Faso, Av.de la nation -08 BP11059 Ouagadougou 08 Burkina. \\ ${ }^{3}$ Autorite de Regulation des Communications Électroniques et des Postes (ARCEP), Ouagadougou Burkina-Faso. \\ ${ }^{4}$ Department of Communications, University of Kara, Togo, Ex ENI road, south-east Kara, about $800 \mathrm{~m}$ from the National $\mathrm{N}^{\circ} 1 ., 43$ Lama, Kara, Togo.
}

\begin{abstract}
We have more innovation on Ethernet wireless links nowadays. The introduction of the E-band and V-Band provide more spectral capacity to build microwave links with high throughput. That is done with Ethernet and MPLS in a microwave technology. In this paper we describe the evolution, application and best opportunities to use microwave in E-band frequency for the $2 \mathrm{G} / 3 \mathrm{G} / 4 \mathrm{G} / 5 \mathrm{G}$ mobile networks, for fiber backup links, enterprise networks and VIP lines. We present the air link capacity, the layer 2 throughput with and without IFG and preambule suppression. The results by simulations prove the possibility to have with one channel, an air link capacity of $986 \mathrm{Mbps}$ in the E-band frequency with $99.999 \%$ annual availability for path length range $0.89 \mathrm{~km}$ to $1.62 \mathrm{~km}$ in West Africa.
\end{abstract}

Keywords: Microwave; Wireless; E-band; V-band

\section{Introduction}

With the ongoing evolution of microwave technology, it is possible to build best links (high capacity and best performance) with low cost for the mobile network, fixed and enterprise networks service transports. Despite massive investments in fiber in some countries, microwave links will remain a technically and economically relevant solution for the backhauling. We have muny innovations in microwave domain: multi access on user network interface, MIMO antenna, XPIC, higherorder QAMs (1024QAM, 2048QAM, 4096QAM and 8192QAM), the ACM (Automatic Coding Modulation), 11la, LAG to increase the link capacity and performance [1]. The microwave technology can support multiples access (E1, STM1, Fast-Ethernet, Gigabit-Ethernet and 10 Gigabit Ethernet). The microwave transmission network support layer 2, layer 2.5 and Layer 3 protocols to provide the same services such as the switch-router, OSN (Optical service Node).

The data throughput on Ethernet wireless links is usually being quoted at Layer 1 (L1) rather than Layer 2 (L2) [2]. On the L1, the microwave transmission also uses pipes. The capability of the pipes is the air- interface capacity. The air-interface capacity depends on the modulation, the channel spacing and the code efficiency. IEEE defines the throughput as the maximum data transmitting and receiving rate of a device without frame loss.

The network Quality of service (QoS) is characterized by four Key Performance Indicators (KPI): packet loss, delay, jitter (the variation of delay over time) and the availability [3]. The mains parameters to consider for any network design to ensure the QoS are the Performance, the Reliability, the Scalability and the Security. These four parameters are fundamental to provide a best quality of services to the end users. For the microwave links the QoS provided depend on several factors that we can group in two parts: services implementations parameters and the radio frequency (RF) performances parameters. Before the RF design, it is better to illustrate the types of services that we will provide to the users and evaluate the link capacity for the all hops of the network. This step is important and allows the types of features to choice on the IDUs for the all services implementation (E1oEth, STM1oEth, full Ethernet, L2VPN, and L3VPN) and the resilience configuration (ERPS, RSTP, MSTP, MPLS-TP). The RF performance depends on the environment and the device. The network design is needed in order to consider the transmission distance for the frequency choice. The Free Space Path Loss, terrain and weather (rain, snow, and fog) are the three environmental factors affecting the space loss.

Our contribution in this paper is to present the evolution of microwave technology, in consideration of each services and the layer 2 throughput during the link design to have end to end capacity for the network quality and resilience. Also we implemented a simulation on E-band frequency in West Africa area to prove the importance to use this band for next generation mobile backhaul.

\section{On the Microwave Technology}

\section{Microwave transmission system application}

For Services backhaul at mobile base station, microwave devices are mainly used in mobile station to transmit signal to the BSC, RNC, MME or APF/UPF for switching (Figure 1).

Microwave communication technology is widely applied to scenarios where building optical networks is costly. When optical fibers are difficult to deploy due to geographical and other constraints, microwave is often used an alternative. Microwave is often used as the backup link in optical transmission network, enterprise private networks and VIP customer private line (Figure 2).

Microwave technology is increasingly used to provide Carrier Ethernet. The main advantages of Microwave based Ethernet solutions are $[4,5]$ :

*Corresponding author: Sawadogo Moumouni, Department of Communications, Laboratoire de Matériaux et Environnement (LAME), Université Ouaga I, Pr Joseph Ki-Zerbo, Ouagadougou Burkina-Faso, Tel: +22625369960; E-mail: sawadogomouni@hotmail.fr

Received October 30, 2018; Accepted October 31, 2018; Published November 07, 2018

Citation: Moumouni S, Sanou SR, Kebre BM, Doumounia A, Illa K, et al. (2018) Packet Microwave Layer 1 and Layer 2 Throughput in E-band for Mobile Broadband Communications. J Telecommun Syst Manage 7: 173. doi: 10.4172/21670919.1000173

Copyright: (C) 2018 Moumouni S, et al. This is an open-access article distributed under the terms of the Creative Commons Attribution License, which permits unrestricted use, distribution, and reproduction in any medium, provided the original author and source are credited. 


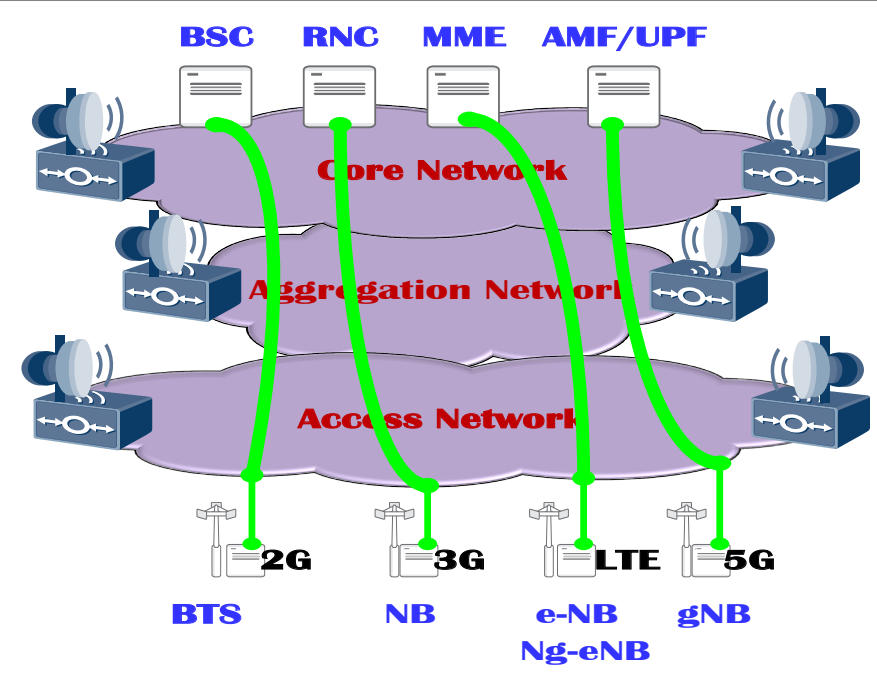

Figure 1: Microwave application for Mobile Network.

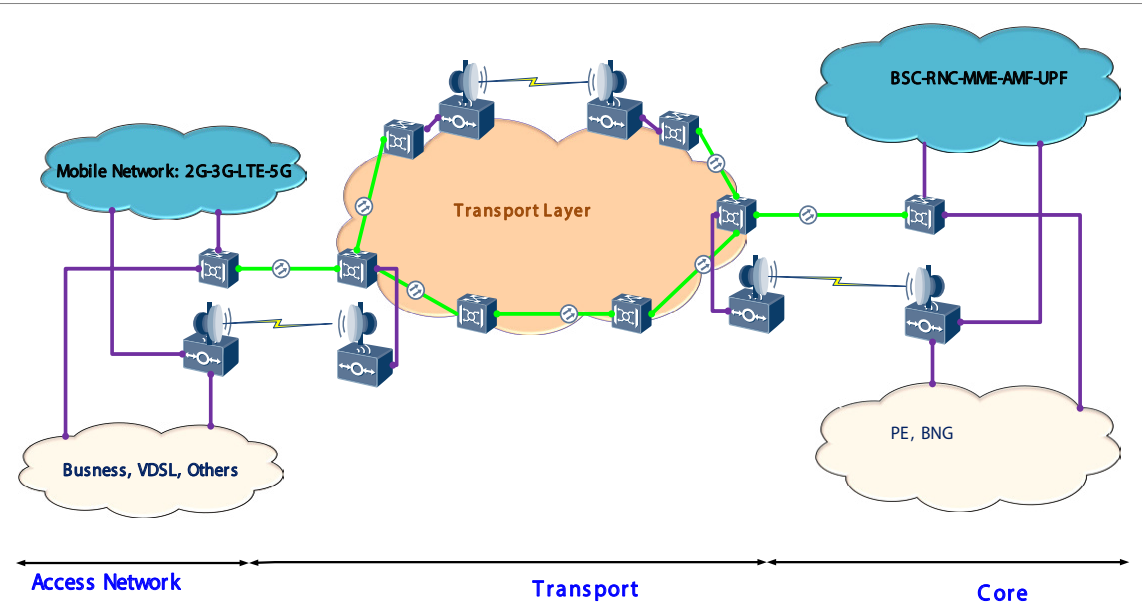

Figure 2: Microwave application for multi-service.

- Rapid deployment time and easily crossed city terrain (no street digging)

- Flexibility (can upgrade, increase capacity or redeploy)

- Cost effective when compared to other approaches

- Offers throughput that rivals fiber for many applications

- Mature carrier-grade solution

- No cable cuts, quicker recovery if damaged

- Better resilience to natural disasters such as floods and earthquakes.

Presently, microwave radio links have been a key point to the successful deployment of modern mobile networks, to the point where over $60 \%$ of mobile base stations worldwide are connected via Microwave [1]. Each radio site needs $25 \mathrm{Mbps}$ and considering $100 \%$ of the radio sites, maximum backhaul capacity required is $150 \mathrm{Mbps}$ for the Multi BTS single RAN 2G/3G/4G [6]. The LTE-A/5G (LTE: 20M-3 cells-4T4R and 5G: 200M-3cells-64T64R) site average rate is 6.39 Gbps. The network bandwidth forecast is illustrated in Table 1.

\section{Microwave frequency band}

ITU-R recommendation on the designation of microwave frequencies is followed by relevant authorities in every country. These countries generally adhere to the ITU-R recommendation completely, but same may include their own standards. Microwave spectrum is divided such as below:

- Common band: $6 \sim 42 \mathrm{GHz}$

- $\quad$ V-band: $57 \sim 66 \mathrm{GHz}$

- $\quad$ E-band:71 76 GHz, 81 86 GHz

- W-band:92 114.25 GHz

- $\quad$ D-band:130 174.8 GHz.

Rain attenuation occurs at all frequencies, but it is negligible at frequencies less than $5 \mathrm{GHz}$ [6]. In the frequency range of $7 \mathrm{GHz}$ to 10 $\mathrm{GHz}$ the attenuation is small and is proportional to rainfall rate $[6,7]$. The low frequencies inferior to $10 \mathrm{GHz}$ will continue to be used for long hop distances and are essential in geographical areas with high rain rates. The figure summarizes the global bands (subject to regional 
Citation: Moumouni S, Sanou SR, Kebre BM, Doumounia A, Illa K, et al. (2018) Packet Microwave Layer 1 and Layer 2 Throughput in E-band for Mobile Broadband Communications. J Telecommun Syst Manage 7: 173. doi: 10.4172/2167-0919.1000173

Page 3 of 8

variations), together with typical maximum link lengths in below Table $2[8]$.

The V-Band is characterized by a continuous block of $9 \mathrm{GHz}$ of spectrum between 57 and $66 \mathrm{GHz}$, oxygen absorption that implies immunity to interference and enhanced frequency re-use, a favourable licence regime, mostly unlicensed or light licensed (country dependent). E-Band enables gigabit-per-second data rates given the huge amount of available spectrum $(10 \mathrm{GHz})$ without any oxygen absorption, thus allowing longer distances compared to $\mathrm{V}$-Band. The places where E-Band is today open for fixed services is indicated in green, in red the places where this band is closed today and in blue the places where the use of E-Band is open, but under review (Figure 3) [9]. E-band satisfies the high-capacity demands of today's networks, and will be suitable during the coming years when $5 \mathrm{G}$ is rolled out. However, in the long term more spectrum will be needed. Standardisation of the W-band (92-114.25 GHz) and D-band (130-174.8 GHz) is ongoing. The bands are not made up of a continuous block of spectrum, but rather a number of blocks.

The total amount of spectrum in $\mathrm{W}$ - and $\mathrm{D}$-band is almost $50 \mathrm{GHz}$, i.e. five times more than in E-band. This is an important asset for the future.

The channel spacing is the difference in channel center frequency between two adjacent channels. According to the ETSI

\begin{tabular}{|l|l|l|l|}
\hline Bandwidth Anticipated & $\mathbf{2 0 1 7}$ & $\mathbf{2 0 2 0}$ & $\mathbf{2 0 2 3}$ \\
\hline 75\% of sites & $150 \mathrm{Mbps}$ LTE20M 2T2R & $300 \sim 600 \mathrm{Mbps}$ LTE40M 2T2R/4T4R & 1 2 Gbps LTE 40 100M 4T4R/8T8R \\
\hline 25\% of Sites & $300 \mathrm{Mbps}$ LTE 40M 2T2R & $0.8 \sim 1 \mathrm{Gbps}$ LTE 40 60M 4T4R/8T8R & 4 5 Gbps LTE 40 100M 4T4R/8T8R 5G100M 64T/64R \\
\hline$<5 \%$ Sites & 1 Gbps LTE 40 60M 4T4R/8T8R & 2 4 Gbps LTE 40M 4T4R 5G100M 64T/64R & 10 20 Gbps 5G100M 64T/64R 5G800M 64T/64R \\
\hline
\end{tabular}

Table 1: Network bandwidth forecast [6].

\begin{tabular}{|c|c|c|c|}
\hline Frequency band & Frequencies, GHz & Typical maximum link length, km & Typical minimum link length, km \\
\hline 0.9 (unlicensed) & $0.902-0.928$ & 100 & - \\
\hline 2.4 (unlicensed) & $2.4-2.5$ & 100 & - \\
\hline 4 & $3.6-4.2$ & 70 & 24 \\
\hline 5 & $4.4-5.0$ & 60 & 16 \\
\hline 5 (unlicensed) & $5.3,5.4$ and 5.8 & 50 & - \\
\hline L6 & $5.925-6.425$ & 50 & 16 \\
\hline U6 & $6.425-7.125$ & 50 & 16 \\
\hline L7 & $7.1-7.75$ & 50 & 10 \\
\hline U8 & $7.75-8.5$ & 50 & 10 \\
\hline 10 & $10-10.7$ & 20 & 10 \\
\hline 11 & $10.7-11.7$ & 20 & 10 \\
\hline 13 & $12.7-13.25$ & 20 & 6 \\
\hline 15 & $14.4-15.35$ & 20 & 6 \\
\hline 18 & $17.7-19.7$ & 20 & 2 \\
\hline 23 & $21.2-23.6$ & 20 & 2 \\
\hline 26 & $24.25-26.5$ & 20 & 2 \\
\hline 28 & $27.5-29.5$ & 15 & 2 \\
\hline 32 & $31.0-33.4$ & 10 & 1.5 \\
\hline 38 & $37.0-40.0$ & 10 & 1 \\
\hline 42 & $40.5-43.5$ & 10 & 1 \\
\hline 60 (unlicensed) & $57.0-66.0$ & 1 & - \\
\hline 80 & $71-76 / 81-86$ & 5 & - \\
\hline
\end{tabular}

Table 2: Typical hop length for different frequency bands, defined by ITU-R radio regulations.

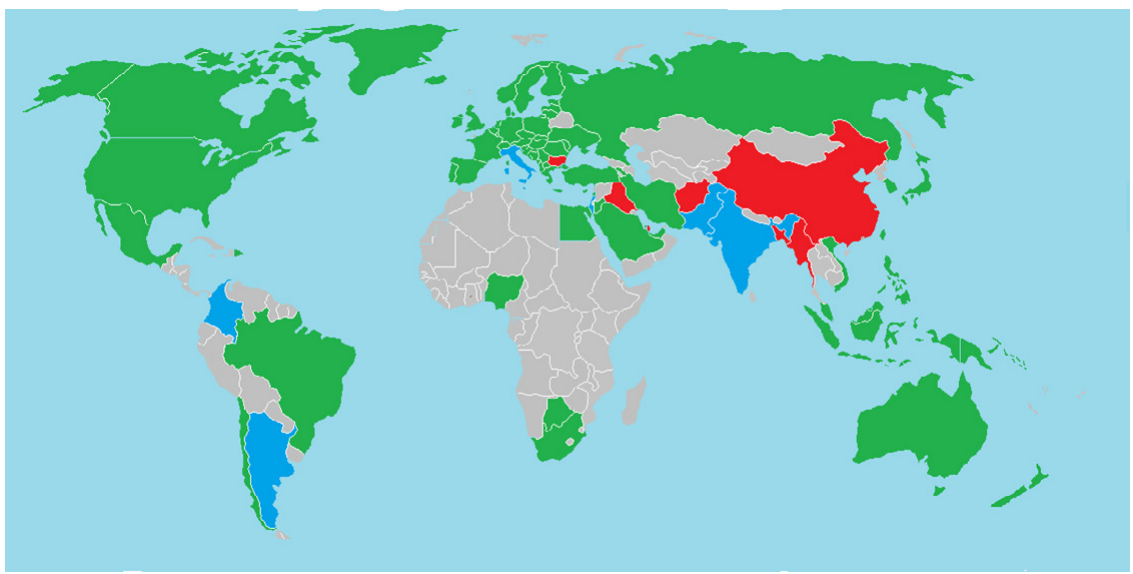

Figure 3: E-Band worldwide situation [9]. 
conventional bands, they are divided into $3.5 / 14 / 28 / 40 / 56 / 112 \mathrm{MHz}$ ... and 10/20/30/40/50 MHz... According to the ANSI. The frequencies resources are naturally limited and need best pacification and optimization during the links design. The keys parameters to consider before any validation of link design after the best inputs are:

- Receive signal (dBm)

- $\quad \mathrm{RX}$ threshold level (dBm)

- Thermal fade margin $(\mathrm{dB})$

- Annual availability

- XPIC value (dB).

There are more professional tools for the microwave links design and we can cite: CTE Phaloss, Huawei iRiver Designer, InfoVista Ellipse, Ericsson TEMS Link Planner, TEOCO Asset Backhaul, Cambium Link Planner. The popular tools are Pathloss provided by CTE (Contract Telecommunication Engineering) and InfoVista Ellipse.

\section{Mobile broadband backhaul topology}

Microwave LOS links can be part of a variety of network architectures. The usual configurations are as follows (Figure 4). The mesh topology and ring topology are very good and provide very good availability, scalability and Provide LTE cell-to-cell connectivity (X2) the network. To optimize the radio frequency spectrum and reduce the Capex, we recommend the ring topology with multi-layer:

- $\quad$ Ring backbone: ITU-T G.8032

- Aggregation Ring: ITU-T G.8032

- Access link or last mile: Ethernet

The Ring Backbone is the major ring and the Aggregation ring are the sub-ring in Figure 5 below. For the ITU-T G.8032 networks (ERPS), the services of the interfaces OAM, IuB, Abis, S1-M, X2 are separated by vlans_ID. It is possible to replace the ERPS protection by MPLS-TP (RFC 6378) with 1:1 or $1+1$ protection and connect the last mile sites by L2VPN.

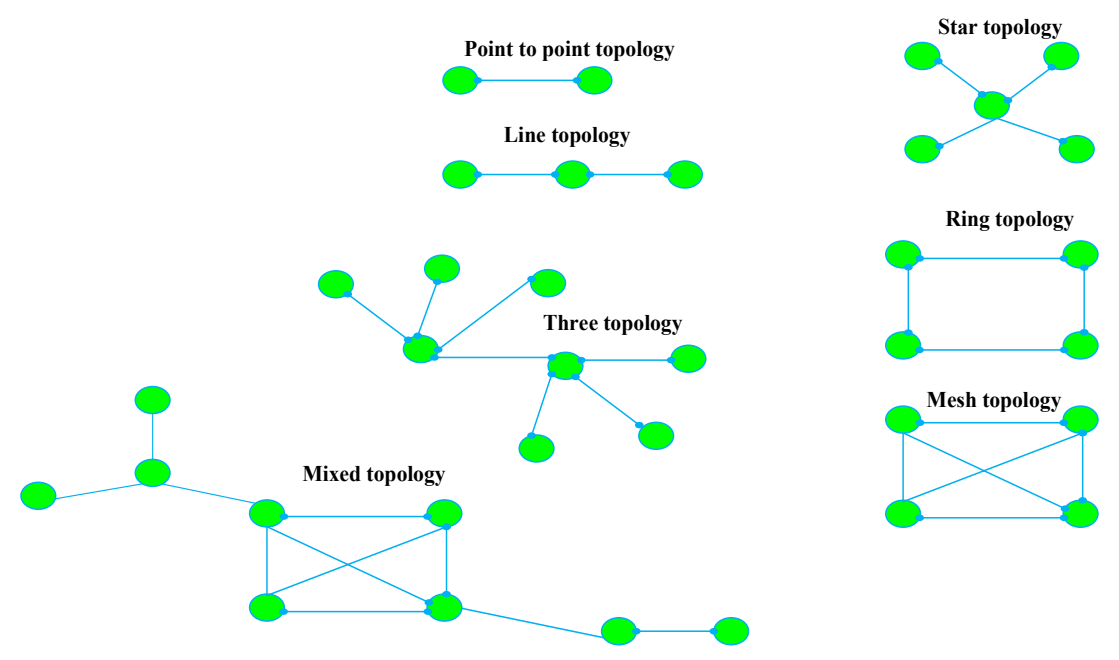

Figure 4: Microwave LOS link network topologies.

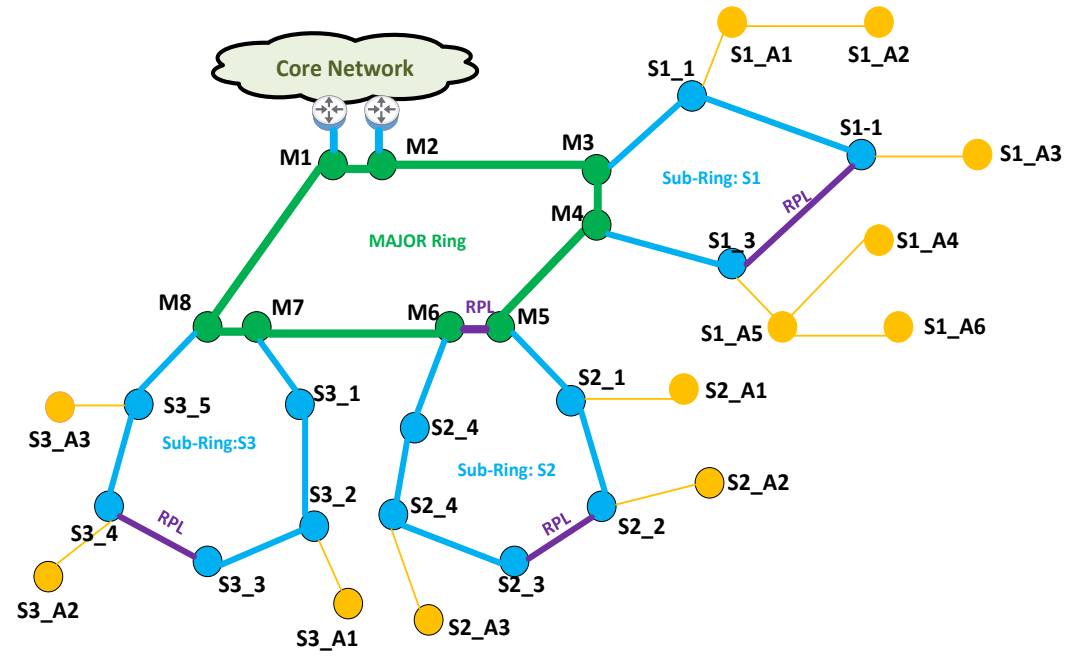

Figure 5: Microwave ring and access Network for mobile Network. 
In Figure 5 the Ring protection link is the Ring link which under normal conditions, i.e., without any failure or request, is blocked (at one end or both ends) for traffic channel, to prevent the formation of loops [10]. The RPL link connect physycaly the RPL Owner to the RPL Neighbor. for each Ring. The RPL must be chosen in such a way as to share equitable the traffic of the Ring in each branch. The traffic for the sub ring $\mathrm{Si}$ is TSi is given by equation:

$$
\operatorname{TSi}(\operatorname{Mbps})=\sum_{j=1}^{J} S i_{A j}+\sum_{k=1}^{K} S i_{k}
$$

- $J$ is the number of access node connected to the sub-ring $i$

- $K$ is the number of node of the sub ring $i$

- $S i \_A j$ is the traffic capacity of the MBTS connected to the access node $j$

- $\quad S i \_k$ is the traffic capacity of the $k$ node of the sub-ring $i$

- The Layer 2 throughput capacity of each link of the sub-ring $i$ is TSi

The traffic of each link of the major ring is TM (Mbps) and is illustrated by equation 10 :

$$
M(M b p s)=\sum_{i}^{I} T S i+\sum_{p=1}^{\frac{P}{2}-2} M i
$$

Or

$$
T M(M b p s)=\sum_{i}^{I}\left(\sum_{j=1}^{J} S i_{-} A j+\sum_{k=1}^{K} S i_{-} k\right)+\sum_{p=1}^{\frac{P}{2}-2} M i
$$

In the eqns. (2) and (3), $\mathrm{P}$ is the number of microwave node of major ring. In our case, we use two microwave of each major site of the ring Backbone.

\section{Techniques for enhancing link capacity}

There are many options to increase the microwave link capacity.
These options for increasing bandwidth can be used alone or in combination:

- Increase the modulation scheme including code efficiency. 8192QAM modulation increases service capacity by $52 \%$ compared to 256QAM. This option decrease the link availability. For this option it is better to use ACM with QoS on priority services.

- XPIC doubles link capacity on a given frequency, saving spectrum and antenna cost. Throughput is doubled due to parallel transmission on two radio links working at the same frequency, but different polarizations.

- Increasing transmission efficiency (air interface usage rate).

- The IFG+Preamble suppression and MAC Header compression

- MIMO 4X4 LOS double the XPIC Throughput

- Multi-band radio solution with E-band single antenna. If the current throughput is $600 \mathrm{Mbps}$, this capacity can exceed 10 Gbps with the traditionnel band $+\mathrm{E}$-band $(18 \mathrm{GHz}+\mathrm{E}$-band or $11 \mathrm{GHz}+\mathrm{E}-$ band) [11].

- Multiservice rings scale capacity in aggregation networks and also provide sub-50 $\mathrm{ms}$ service restoration.

- LAG does link bonding, load balancing transmission over a set of links. It scales link capacity by multiplying links together into a virtual high-capacity microwave link using radio or Ethernet link aggregation techniques. It also provides link protection for additional reliability [12].

\section{Simulation and Result in the E-band Frequency}

\section{Atmospheric gas attenuation and IUT-rain map regions}

In this part we implement the simulations in E-band frequency in West Africa (ITU-R rain region: $\mathrm{C}, \mathrm{E}, \mathrm{P}, \mathrm{K}$ and $\mathrm{N}$ ). In the E-band, the oxygen, water and vapor attenuation is less than V-band (Figures 6 and 7 ).

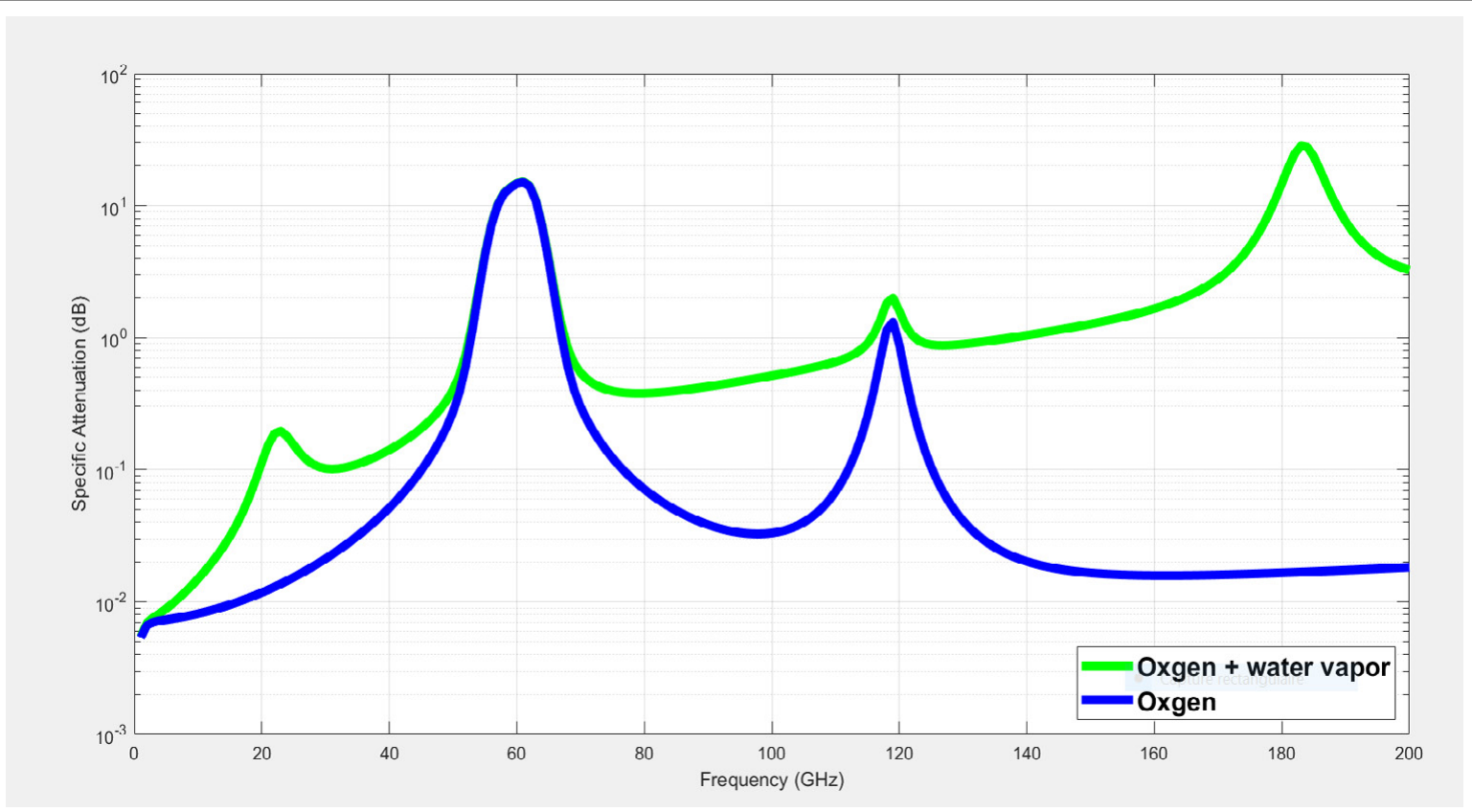

Figure 6: oxygen and water vapor specific attenuation (dB) (source: ITU-R P.676-10-2013). 


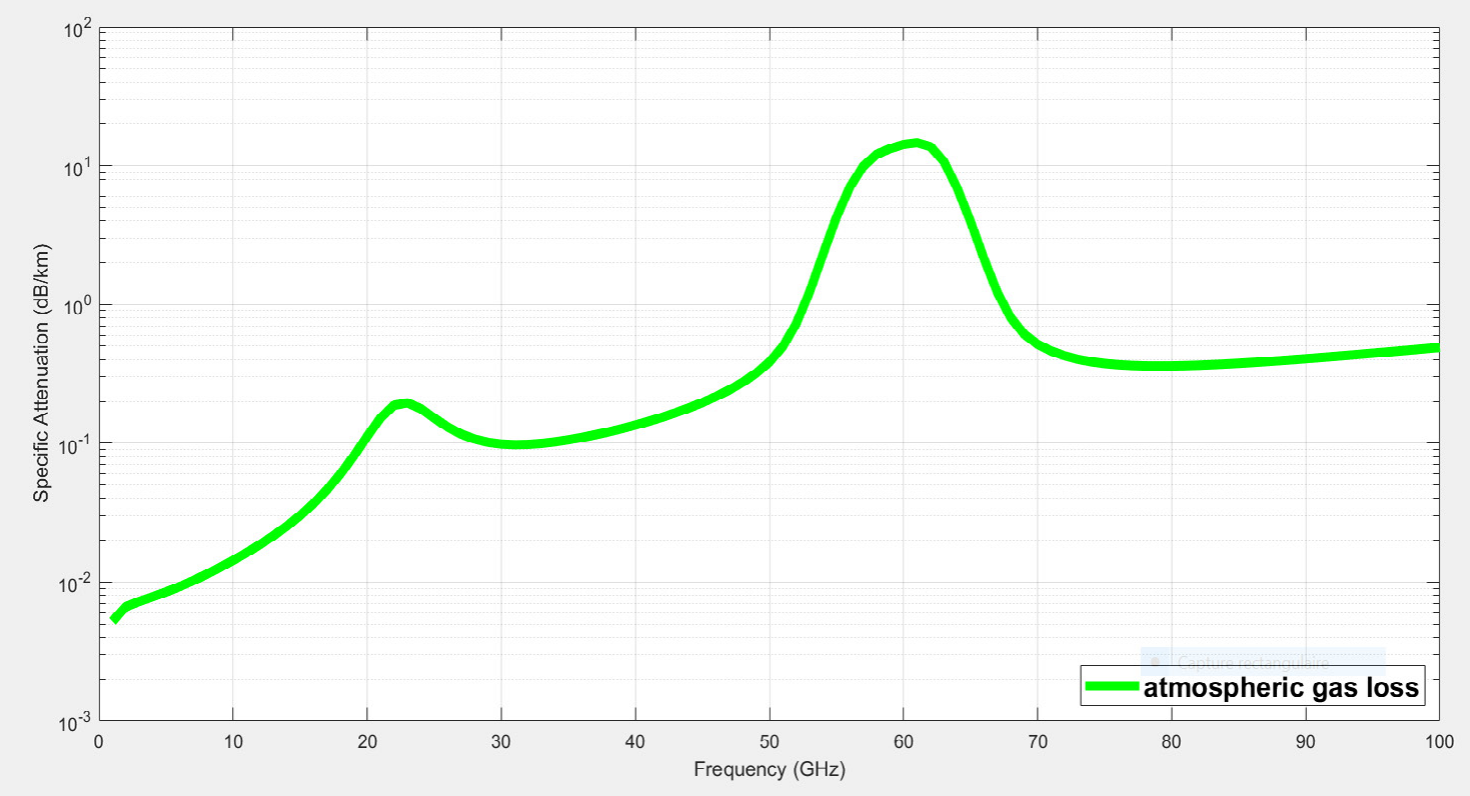

Figure 7: Atmospheric Gas Attenuation (dB/km).

We have also more Bandwidth per channel $(\mathrm{MHz})$ in E-band less than V-band [13].

The ITU-R Rain map zones $\mathrm{C}, \mathrm{E}, \mathrm{P}, \mathrm{K}$ and $\mathrm{N}$ are illustrated in Figure 8 .

\section{Radio design parameters and design results}

We used Pathloss tools in Aviat network cloud for the design. The design parameter are:

- Frequency band: $73 \mathrm{GHz}$ and $83 \mathrm{GHz}$

- Channel Spacing: $250 \mathrm{MHz}$ ETSI

- Modulation: ACM QPSK-64QAM

- Availability objective (\%): $99.999 \%$

- Antenna diameter $0.6 \mathrm{~m}$

- Link polarization: Vertical

- Tx Power: $14 \mathrm{dBm}$.

The results of the design in $\mathrm{K}$ zone at $73 \mathrm{GHz}$ and $83 \mathrm{GHz}$ are illustrated by Figures 9 and 10. The L1 capacity can reach $986 \mathrm{Mbps}$ for one channel $(250 \mathrm{MHz})$. The $\mathrm{L} 2$ throughput depending of the frame size and is given by eqn. (4):

L2 (Mbps) $=\mathrm{L} 1$ * Frame Length/(Frame Length+Preamble+IFG)

Throughput on smallest 64-byte frames is nominally 751.238 Mbit/s (76 percent of L1 capacity). On average size 260-byte frames, throughput is $909.078 \mathrm{Mbit} / \mathrm{s}$ (92 percent). On 1518-byte frames, throughput is $973.17 \mathrm{Mbit} / \mathrm{s}$ (98.7 percent).

With IFG and preamble suppression, plus MAC header compression the L2 throughput is given by eqn. (5).

L2 (Mbps) $=\mathrm{L} 1{ }^{\star}$ Frame Length/(Frame Length $\left.+4-10\right)$

Throughput on smallest 64-byte frames is nominally $1.088 \mathrm{Gbps}$ (44.82 percent of L2 capacity without compression). On average size

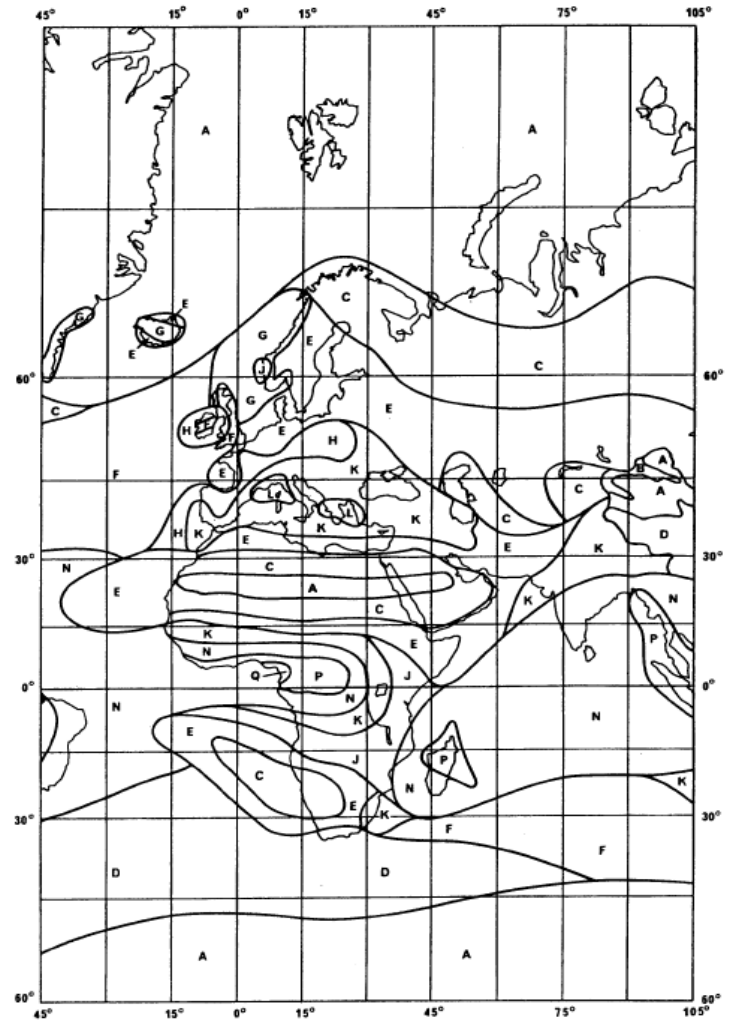

Figure 8: Rain map zone (ITU-R PN.837-1)

260-byte frames, throughput is 1.009 Gbps (11.023 percent). On 1518byte frames, throughput is $989.912 \mathrm{Mbit} / \mathrm{s}$ (1.72 percent).

The table below summarizes the results obtained in region $\mathrm{C}, \mathrm{E}, \mathrm{K}$, $\mathrm{P}$ and $\mathrm{N}$ [14]. The city list for the test are located in Table 3. 
Citation: Moumouni S, Sanou SR, Kebre BM, Doumounia A, Illa K, et al. (2018) Packet Microwave Layer 1 and Layer 2 Throughput in E-band for Mobile Broadband Communications. J Telecommun Syst Manage 7: 173. doi: 10.4172/2167-0919.1000173

\begin{tabular}{|c|c|c|c|c|}
\hline Modulation & $\begin{array}{l}\text { Received Signal } \\
(\mathrm{dBm})\end{array}$ & Capacity (Mbps) & Availability (\%) & $\begin{array}{l}\text { Outage Time } \\
\text { (Days ssHH:mm:ss) }\end{array}$ \\
\hline QPSK & -14.83 & 363 & 99.99969 & $00000: 01: 39$ \\
\hline 16QAM & -15.83 & 648 & 99.99956 & 000 00:02:19 \\
\hline 64QAM & -17.83 & 986 & 99.999 & $00000: 05: 14$ \\
\hline \multicolumn{5}{|c|}{ Availability (QPSK) } \\
\hline \multicolumn{2}{|c|}{ Annual Multipath (\%): } & 100.00000 & & 100.00000 \\
\hline \multicolumn{2}{|c|}{ Reliability Calc / Rain: } & \multicolumn{3}{|c|}{$51 \mathrm{~mm} / \mathrm{hr}$ - ITU-R P.530 } \\
\hline \multicolumn{2}{|c|}{ Annual Rain (\%): } & \multicolumn{3}{|c|}{99.99969} \\
\hline \multicolumn{2}{|c|}{ Annual Multipath + Rain (\%): } & \multicolumn{3}{|c|}{99.99969} \\
\hline
\end{tabular}

K Factor: 1.33 - F1 Clearence: $100 \%$

Figure 9: $70 \mathrm{GHz} / 250 \mathrm{MHz}$, Path length $1.24 \mathrm{~km}$ (Region K).

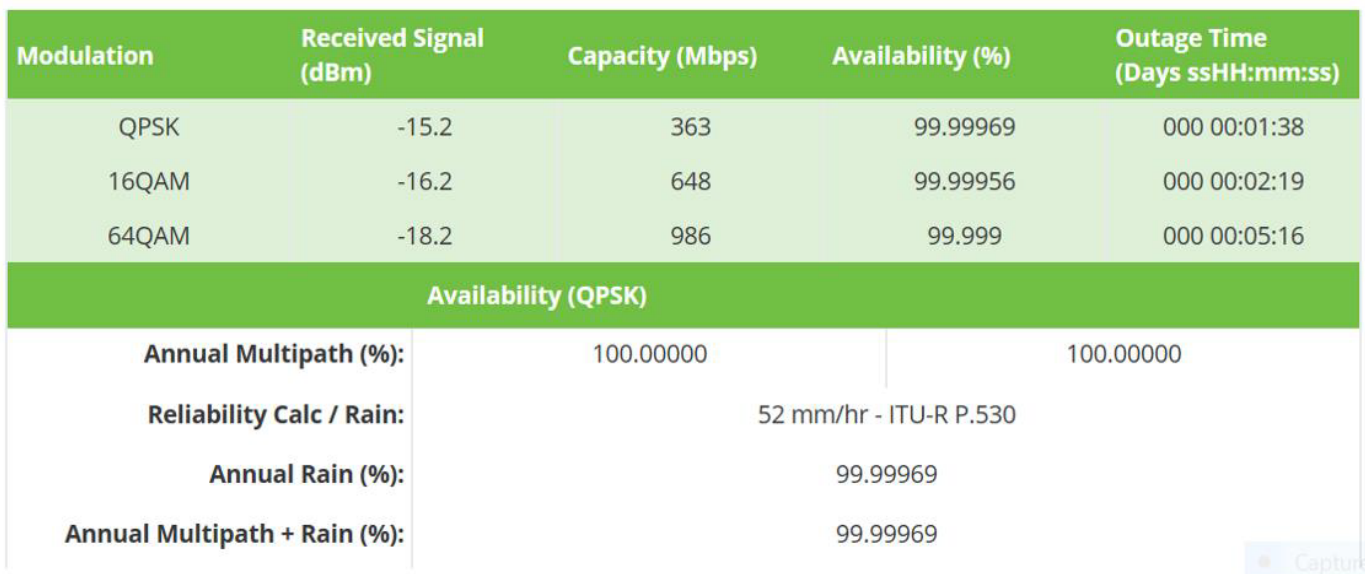

K Factor: 1.33 - F1 Clearence: 100\%

Figure 10: $80 \mathrm{GHz} / 250 \mathrm{MHz}$, Path length $1.16 \mathrm{~km}$ (Region K).

\begin{tabular}{|l|l|l|l|l|}
\hline City & Latitude (O) & Longitude(O) & Region & Country \\
\hline Abidjan & 5.353 & -4.03175 & P & ITU-R P.530 \\
\hline Koidu & 8.6448 & -10.9678 & $\mathrm{~N}$ & $75 \mathrm{~mm} / \mathrm{h}$ \\
\hline Nouakchott & 18.116 & -15.9453 & C & Sierra Leone \\
\hline Ouagadougou & 12.318 & $\mathrm{~mm} / \mathrm{h}$ & Mauritania \\
\hline SEVARE & 14.5299 & -1.5214 & B & $30 \mathrm{~mm} / \mathrm{h}$ \\
\hline
\end{tabular}

Table 3: Test area.

The results of Tests for each area are mentioned in Table 4. With these results, we can reach $986 \mathrm{Mbps}$ with one channel $(250 \mathrm{MHz})$. This capacity can reach 15.77 Gbps with 2 x $500 \mathrm{MHz}$ channel size with XPIC technology. Then this capacity is sufficient to build ITU-T G.8032 network to connect 4G/5G base stations.

\section{Conclusion}

The next generation is gigabit traffic and 10-gigabit traffic with Ethernet network or IP/MPLS and the microwave solution is the low cost solution. Services backhaul at mobile base station, enterprise private networks and VIP costumer private line, fiber link backup can use Ethernet wireless links. Before the link design, it is better to know

\begin{tabular}{|l|l|l|l|l|}
\hline Region & Modulation & Frequency & Path Length & Availability \\
\hline $\mathrm{C}$ & 64QAM & $70 \mathrm{GHz}$ & $1.62 \mathrm{~km}$ & $99.9990 \%$ \\
\hline $\mathrm{C}$ & 64QAM & $80 \mathrm{GHz}$ & $1.5 \mathrm{~km}$ & $99.99901 \%$ \\
\hline $\mathrm{E}$ & 64QAM & $70 \mathrm{GHz}$ & $1.27 \mathrm{~km}$ & $99.99901 \%$ \\
\hline $\mathrm{E}$ & 64QAM & $80 \mathrm{GHz}$ & $1.17 \mathrm{~km}$ & $99.99904 \%$ \\
\hline $\mathrm{K}$ & 64QAM & $70 \mathrm{GHz}$ & $1.24 \mathrm{~km}$ & $99.999 \%$ \\
\hline $\mathrm{K}$ & 64QAM & $80 \mathrm{GHz}$ & $1.60 \mathrm{~km}$ & $99.999 \%$ \\
\hline $\mathrm{P}$ & 64QAM & $70 \mathrm{GHz}$ & $0.95 \mathrm{~km}$ & $99.99901 \%$ \\
\hline $\mathrm{P}$ & 64QAM & $80 \mathrm{GHz}$ & $0.89 \mathrm{~km}$ & $99.99903 \%$ \\
\hline $\mathrm{N}$ & 64QAM & $70 \mathrm{GHz}$ & $0.99 \mathrm{~km}$ & $99.99902 \%$ \\
\hline $\mathrm{N}$ & 64QAM & $80 \mathrm{GHz}$ & $0.95 \mathrm{~km}$ & $99.99902 \%$ \\
\hline
\end{tabular}

Table 4: Tests results E-band, $73 \mathrm{GHz}$ and $83 \mathrm{GHz}$. 
Citation: Moumouni S, Sanou SR, Kebre BM, Doumounia A, Illa K, et al. (2018) Packet Microwave Layer 1 and Layer 2 Throughput in E-band for Mobile Broadband Communications. J Telecommun Syst Manage 7: 173. doi: 10.4172/2167-0919.1000173

Page 8 of 8

what type of services we will provide at Layer 2 or 2.5 and the packet size. After, we chose the channel spacing and the modulation to provide the air link capacity necessary to support the L2 throughput without frame loss. In this paper, we presented the topology recommended to have best resilience of the transport. However, the E-band and V-band spectrum are not available in many countries of Africa. It is therefore interesting to think of the regulation of this spectrum for every mobile broadband services. The results of simulations prove the opportunities to use the E-band frequency for short links in West Africa. The better zone for the E-band used is the region C (Nouakchott). However this simulation can be extend in throughout and the link capacity funded can be increased by many technical aggregation such as XPIC, LAG, and MIMO technology.

\section{References}

1. Huawei, Microwave \& mm-wave: From today to tomorrow, February. 2016.

2. Aviat Network, "ETHERNET DATA THROUGHPUT", March. 2010.

3. Trevor Manning, Microwave Radio Transmission design guide, Artech House 1999.
4. MEF, Microwave Technologies for Carrier Ethernet Services, JANUARY, 2011

5. Trevor Manning, Microwave Radio Link Performance.

6. Ali Doumounia and all, Rainfall monitoring based on microwave links from cellular Telecommunication networks: First results from a West African test bed. Geophysics. Res Lett 41, 6016-6022.

7. Abdollah Gasemi - Ali Abeda, Propagation Engineering in wireless Communications.

8. Morgan Kurk, the theory, practices and technologies that link the wireless world, 2017.

9. Ericsson, Ericsson Microwave Outlook, 2017.

10. ITU-T G.8032/Y.1344, Ethernet Ring Protection Switching, 06/2008.

11. Pietro Nava, IMT Backhaul, 2018.

12. Alcatel, packet microwave boosting capacity for long-term growth, 2012.

13. Report ITU-R F.2323-0, Fixed service use and future Trends, 2014.

14. Rec. ITU-R PN.837-1, characteristics of precipitation for propagation modeling 